\title{
In-Situ Impregnation of Copper Nanoparticles on Palm Empty Fruit Bunch Powder
}

\author{
Ridzuan Ramli1 ${ }^{*}$, Md. Maksudur Rahman Khan², Rosli Mohd Yunus', \\ Huei Ruey Ong 1,2, Rohaya Mohamed Halim ${ }^{1}$, Astimar Abdul Aziz ${ }^{1}$, \\ Zawawi Ibrahim $^{1}$, Nahrul Hayawin Zainal' \\ ${ }^{1}$ Malaysian Palm Oil Board (MPOB), No. 6, Persiaran Institusi, Kajang, Malaysia \\ ${ }^{2}$ Faculty of Chemical and Natural Resources Engineering, Universiti Malaysia Pahang, Kuantan, Malaysia \\ Email: ${ }^{\text {ridzco@gmail.com }}$
}

Received 18 May 2014; revised 21 June 2014; accepted 9 July 2014

Copyright (C) 2014 by authors and Scientific Research Publishing Inc.

This work is licensed under the Creative Commons Attribution International License (CC BY).

http://creativecommons.org/licenses/by/4.0/

(c) (i) Open Access

\begin{abstract}
Copper nanoparticles were impregnated onto oil palm empty fruit bunch (EFB) powders via in-situ sol-gel method. The impregnation and interfacial interaction of copper nanoparticles with EFB were analysed by fourier transformed infrared spectroscopy (FTIR), X-ray diffraction (XRD), field emission scanning electron microscopy (FESEM), energy dispersive X-ray (EDX) and atomic force microscopy (AFM). The interaction of copper nanoparticles with the surface functional groups of EFB powders was identified by FTIR analysis. The peak shift of $\mathrm{O}-\mathrm{H}$ and $\mathrm{C}-\mathrm{O}$ functional groups indicated the interaction between EFB and copper nanoparticles. Besides that, XRD and EDX analysis confirmed the formation of copper nanoparticles on EFB powder. Due to the copper impregnation, the crystallinity of the EFB was increased as shown by XRD. The particles size of nanoparticles was analysed via TEM and AFM where the sizes were in the range of $60-100 \mathrm{~nm}$. These findings strongly suggest that, copper nanoparticles impregnated EFB powders can be synthesized via insitu sol gel method.
\end{abstract}

\section{Keywords}

Copper Nanoparticles, In-Situ, Empty Fruit Bunch, Sol-Gel

\footnotetext{
${ }^{*}$ Corresponding author.
}

How to cite this paper: Ramli, R., Khan, M.M.R., Yunus, R.M., Ong, H.R., Halim, R.M., Aziz, A.A., Ibrahim, Z. and Zainal, N.H. (2014) In-Situ Impregnation of Copper Nanoparticles on Palm Empty Fruit Bunch Powder. Advances in Nanoparticles, 3, 65-71. http://dx.doi.org/10.4236/anp.2014.33009 


\section{Introduction}

In recent years, cellulose fiber has gained importance to meet the demand of environmental friendly, low cost and biocompatible products in composites, medical supplies, textiles, packaging, energy storage, electronic devices and biomedical materials [1] [2]. However, due to its high hydrophilic nature, poor mechanical strength and non-antimicrobial activity, cellulose fiber cannot be used directly in versatile application [3]. The hydrophilic surfaces and porous structure of EFB fiber lead to undesired air permeability and sweat absorption properties which induce microorganisms’ growth. Chemicals such as halogen ion complexes, metal salt and metal derivatives have been used to provide antibacterial activity to cellulose fibers [4]. Unfortunately, the antibacterial properties of fibers treated with these compounds degrade with time, and may pose harm to humans [5]. Recently, a number of researchers have used noble metal nanoparticles to improve the mechanical and antimicrobial properties of fiber [3] [6]-[8]. To fabricate metal nanoparticles loaded fibers, the fibers usually were immersed in metal nanoparticles-containing aqueous solution before being treated with conventional pad-dry-cure process [9]. Another approach to fabricating metal nanoparticles loaded fiber was prepared by reduction of metal salt which was then absorbed in fiber [10]. However, this method of preparation was limited in application due to possible dropped off of nanoparticles from fibers owing to the very weak interaction of nanoparticles towards the fibers.

In this context, the aim of the present research was to produce copper nanoparticles incorporated on EFB fiber via in-situ method. Field emission scanning electron microscope (FESEM) and atomic force microscopy (AFM) were used to determine sample's external morphology. Energy dispersive X-ray (EDX) was applied to identify the atomic percentage content of the main elements. X-ray diffraction (XRD) was used to provide information about the crystalline structure and orientation of the materials making up the samples. Fourier Transform Infrared Spectroscopy (FTIR) was used to identify the influence of copper nanoparticles on EFB fiber.

\section{Experimental}

\subsection{Materials}

EFB fibers used in this research were collected from Malaysia Palm Oil Board (MPOB), Malaysia. Copper (II) chloride salt $\left(\mathrm{CuCl}_{2} \cdot 2 \mathrm{H}_{2} \mathrm{O}\right)$, hydrazine monohydrate $\left(\mathrm{N}_{2} \mathrm{H}_{4} \cdot \mathrm{H}_{2} \mathrm{O}\right)$, ascorbic acid, anhydrous methanol, sodium hydroxide $(\mathrm{NaOH})$ and acetic acid and were obtained from Sigma-Aldrich, USA and used without further purification.

\subsection{Alkaline Treatment of EFB Fibers}

Raw EFB was initially washed by using D.I water to remove dirt and ash. The washed raw EFB were kept in an oven at $60^{\circ} \mathrm{C}$ for $24 \mathrm{~h}$ for drying. Fresh solutions of $5 \% \mathrm{NaOH}$ were prepared and EFB fibers were immersed for $24 \mathrm{~h}$. After $24 \mathrm{~h}$, the samples were taken out and cleaned by using 1\% acetic acid solution and washed several times with distilled water to remove chemical residue. The washed samples were air dried for $2 \mathrm{~h}$ and then kept in an oven at $60^{\circ} \mathrm{C}$ for $24 \mathrm{~h}$.

\subsection{Preparation of EFB Powder}

The dried treated EFB fibers were grinded with a grinder (RETSCH Ultra Centrifugal Mill ZM 200) and sieved by using sieving shaker (RETSCH, AS 200 Basic). The $40-50 \mu \mathrm{m}$ size particles were separated and kept in PP bag for further experiment.

\subsection{In-Situ Impregnation of Copper Nanoparticles on EFB Powder}

The impregnation of copper nanoparticles on EFB powder was prepared by sol-gel method [11] [12]. Equal volume $(50 \mathrm{~mL})$ of DI water and anhydrous methanol was mixed in a capped bottle and stirred using a magnetic stirrer at room temperature. Subsequently, $\mathrm{CuCl}_{2} \cdot 2 \mathrm{H}_{2} \mathrm{O}(50 \mathrm{mg})$ and ascorbic acid (1.035 g) were added to the solution. A required amount of EFB powder was added into the solution and $2 \mathrm{~mL} \mathrm{of} \mathrm{N}_{2} \mathrm{H}_{4} \cdot \mathrm{H}_{2} \mathrm{O}(64 \%)$ was injected into the reaction mixture with continuous stirring for $2 \mathrm{~h}$. After that, the mixture was transfer to sonicator bath for further reaction at $60^{\circ} \mathrm{C}$ until a paste was formed. The paste samples were kept in vacuum oven at $60^{\circ} \mathrm{C}$ for drying. The dried samples were kept in PP bag for analysis. 


\subsection{Fourier Transform Infrared Spectroscopy (FTIR)}

FTIR (PerkinElmer) was used to analysis all samples. Fixed amount of samples were mixed with KBr and FTIR spectrum was recorded in the range of $400-4000 \mathrm{~cm}^{-1}$.

\subsection{X-Ray Diffractometry (XRD)}

XRD data were collected by using a RigakuMiniFlex II (30 kV and $15 \mathrm{~mA}$ ), Japan, equipped with computercontrolled software to set up the apparatus and analyse the data. To prepare the disc specimen of the samples, 1 g of samples were compressed in a cylindrical mold with a pressure of $1 \mathrm{MPa}$. The specimens were step-wise scanned over the operational range of scattering angle $(2 \theta)$ between $10^{\circ}$ to $50^{\circ}$, with a step of $0.02^{\circ}$. The data were recorded in terms of the diffracted X-ray intensity $(I)$ versus $2 \theta$. The X-ray crystallinity, $X_{\mathrm{X} \text {-ray }}$, was calculated by the help of Sengal's method with the following equation [13]:

$$
X_{\text {X-ray }}=\left(\frac{I_{002}-I_{a m}}{I_{002}}\right) \times 100 \%
$$

where $I_{002}$ is the maximum intensity of 002 reflections from the crystalline and amorphous components, and $I_{a m}$ is the minimum intensity of diffraction from the amorphous part of the EFB fibers. During the calculation, the height of (002) peaks were used at a $2 \theta \approx 22^{\circ}$, while the intensity of $I_{a m}$ was taken from the minimum intensity between the (002) and (110) peaks at a $2 \theta \approx 16^{\circ}$.

\subsection{Morphology}

Cu-EFB powders were investigated by FESEM equipped with EDX of JEOL JSM-7600F, USA. AFM analysis was conducted using NT-MDT AFM in close contact mode.

\section{Results and Discussion}

Figure 1 illustrates the FTIR spectra of EFB, 0.5 wt\% Cu-EFB and 1 wt\% Cu-EFB fibers, recorded as the transmittance (\%) versus frequency in the range of $4000-400 \mathrm{~cm}^{-1}$. As shown in Figure 1, the spectra demonstrate a number of absorption peaks, representing the multipart of the samples. The FTIR spectrum analysis displayed broad bands at 3400 - $3200 \mathrm{~cm}^{-1}$, which corresponds to the hydrogen bonded O-H groups [14]-[16]. The adsorption band of O-H groups of EFB, 0.5 wt\% Cu-EFB and 1 wt\% Cu-EFB fibers appear at $3448 \mathrm{~cm}^{-1}, 3442$ $\mathrm{cm}^{-1}$ and $3440 \mathrm{~cm}^{-1}$, respectively, showing 8 units red shift of this polar group. This shifting of frequency indicates that EFB assist in coordinate with $\mathrm{Cu}^{2+}$ ions [6]. Furthermore, $\mathrm{C} \equiv \mathrm{C}$ stretching vibration in 0.5 wt\% Cu-EFB and $1 \mathrm{wt} \% \mathrm{Cu}-\mathrm{EFB}$ fibers were found at $2150 \mathrm{~cm}^{-1}$, where this peak was not found in EFB spectrum. The $\mathrm{C} \equiv \mathrm{C}$ group was formed after the reaction, it seem that the reaction was occurred between hydrazine (reducing agent) and EFB. Besides that, ester bond of EFB (cellulose) at $1052 \mathrm{~cm}^{-1}$ was shifted to $1060 \mathrm{~cm}^{-1}$ after nanoparticles formed. This amount of shift indicated the formation of copper nanoparticles on EFBw hich might be due to the electrostatic attraction between EFB and Cu. The other significant peak was at $896 \mathrm{~cm}^{-1}$ which assigned to the C-O stretching vibration of amorphous cellulose [17]. The intensity of $896 \mathrm{~cm}^{-1}$ (amorphous C-O) peak was decreased as copper concentration increased. This can be explained by the cover of copper nanoparticleson cellulose surface after formation.

The XRD of EFB, 0.5 wt\%, 1 wt\% Cu-EFB and copper nanoparticles were illustrated in Figure 2. The important peak position for amorphous and crystalline parts of cellulose were analysed and the data were presented in Table 1. The noticeable strong crystalline peak for EFB powder was observed around $2 \theta=22.2^{\circ}$, which represented the crystallographic (002) plane of cellulose materials of EFB [3]. The position of (002) peak might be shifted to higher angle $(2 \theta)$ after treatment. This shifting suggests that copper nanoparticles were present on the internal pore walls of EFB fibers [18]. Besides that, new peak appears at $2 \theta=42.3^{\circ}$ for Cu-EFB powders which attributed to (111) cu plane from the cubic copper crystal [19]. This confirmed that, copper nanoparticles were impregnated on EFB powder. Moreover, at copper nanoparticles XRD spectrum, one single peak at $42.3^{\circ}$ was detected which definite the appearance of $\mathrm{Cu}$ phase in the sample [20]. From XRD profile it definite that after impregnation, no $\mathrm{CuO}$ peak was detected. This finding indicates that, the copper nanoparticles in the composite were stable. The estimated percentage of crystallinities of EFB, $0.5 \mathrm{wt} \%$ and $1 \mathrm{wt} \% \mathrm{Cu}$-EFB powder were presented in Table 1, which exhibits an increment in crystallinity after impregnation of copper nanoparticles. 


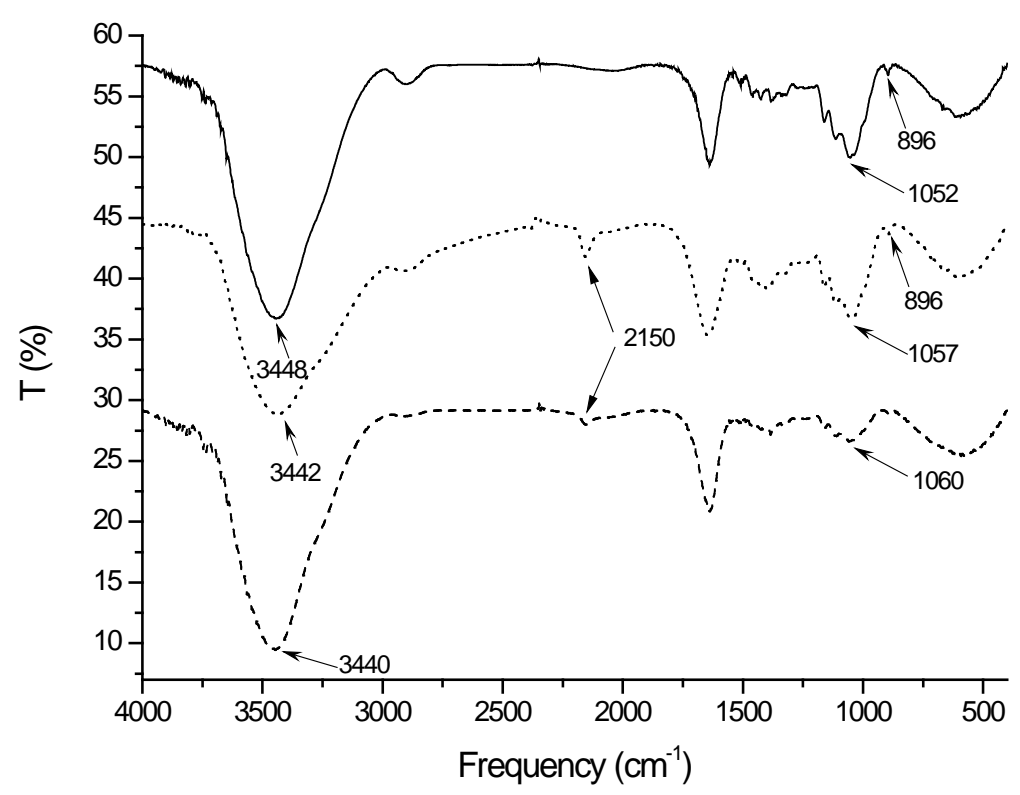

Figure 1. FTIR spectra of EFB fibre (straight line), 0.5 wt\% Cu-EFB fibre (dot line) and $1 \mathrm{wt} \% \mathrm{Cu}$-EFB fibre (dash line).

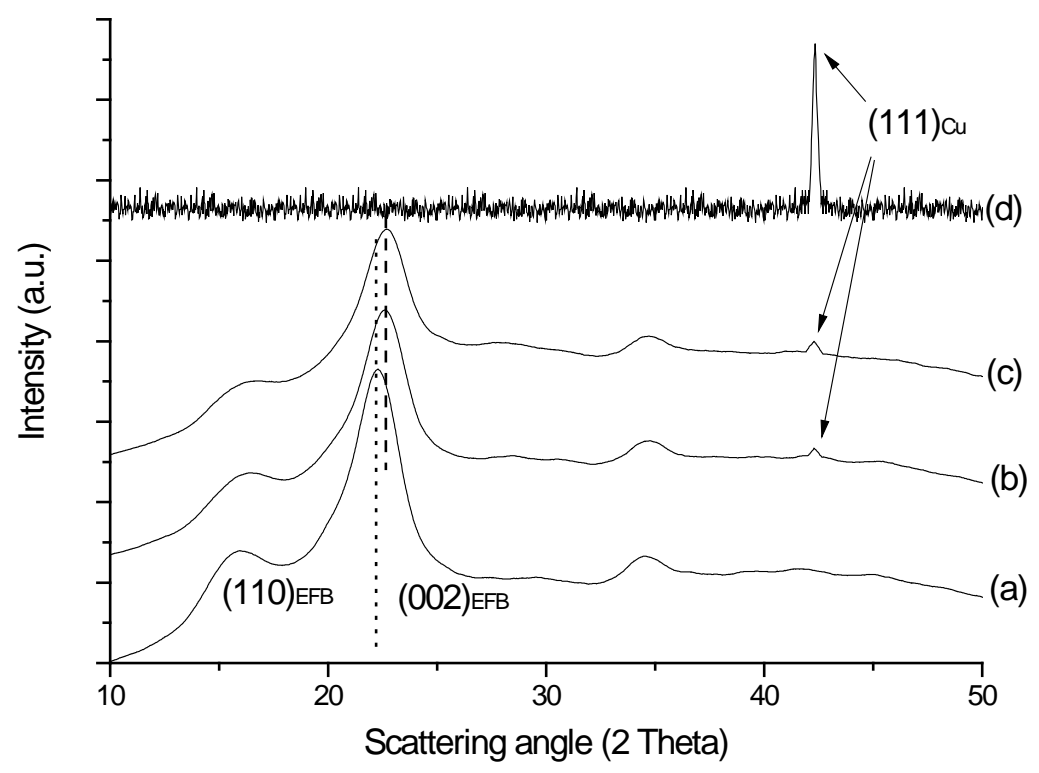

Figure 2. Wide angle XRD profile of EFB (a); 0.5 wt\% Cu-EFB (b); 1 wt\% $\mathrm{Cu}-\mathrm{EFB}$ (c) powders and Cu nanoparticles (d).

Table 1. Crystalline parameters obtained from XRD diffractograms of variously treated EFB powder.

\begin{tabular}{cccc}
\hline Sample & Peak position $(2 \theta)$ & Intensity (counts/s) & Crystallinity (\%) \\
\hline EFB & 15.8 (amorphous) & 1153.1 & 51.7 \\
& 22.2 (crystalline) & 2392.1 & 59.1 \\
\multirow{2}{*}{1 wt\% Cu-EFB } & 16.4 (amorphous) & 806.2 & 60.1 \\
\hline
\end{tabular}


Figures 3(a)-(d) demonstrated the surface roughness of unloaded and loaded copper nanoparticles EFB powders in 2D and 3D topographs. From Figure 3(a) and Figure 3(b), it can be seen that small spherical nanoparticles with size $\sim 100 \mathrm{~nm}$ were formed throughout the surface of EFB. The existences of nanoparticles on EFB were confirmed via 3D topographs (Figure 3(c) and Figure 3(d)) where the thickness of the surface was increased.

The morphologies and sizes of copper nanoparticles on the EFB and EFB were monitored by FESEM as shown in Figure 4(a) and Figure 4(b), respectively. The sizes of particles were $\sim 60 \mathrm{~nm}$. In Figure 4(a), it can be seen that the surface of EFB was homogenously coated with copper nanoparticles. The EDX analysis confirms the copper nanoparticles incorporation on the EFB powder, since a certain amount of copper was traced in the profile of Figure 4(c). Additionally, EFB powders contain major chemical elements like carbon (C) and oxygen $(\mathrm{O})$.

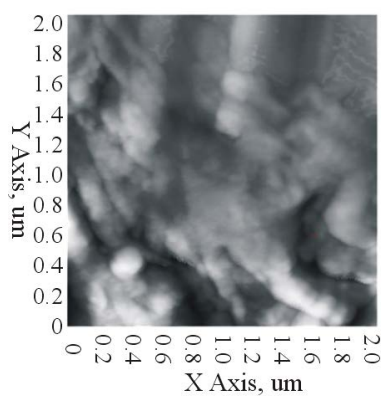

(a)

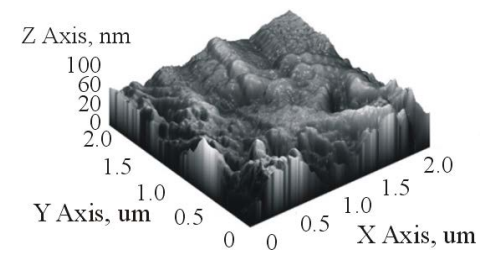

(c)

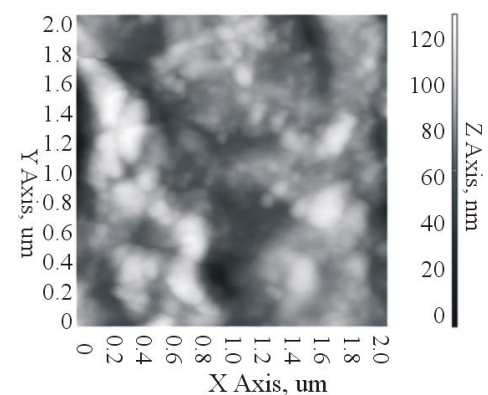

(b)

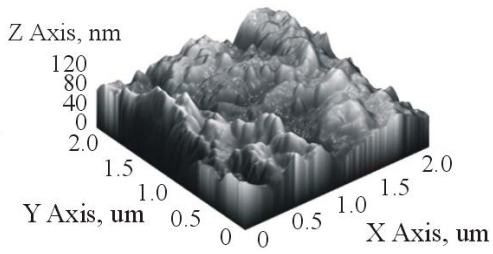

(d)

Figure 3. AFM 2D phase diagram of untreated EFB (a); 1 wt\% Cu-EFB (b) and 3D surface topography of untreated EFB (c); 1 wt $\%$ Cu-EFB (d).

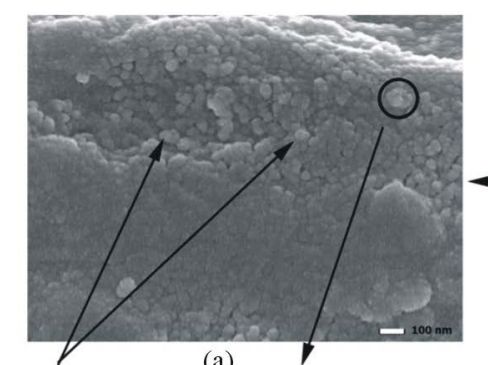

Copper

Nanoparticle

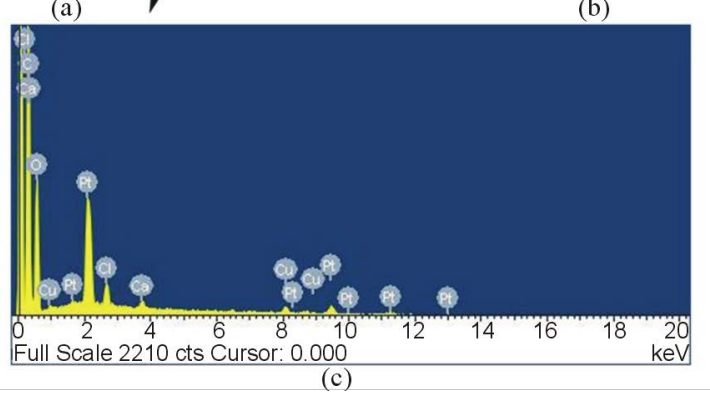

(c)

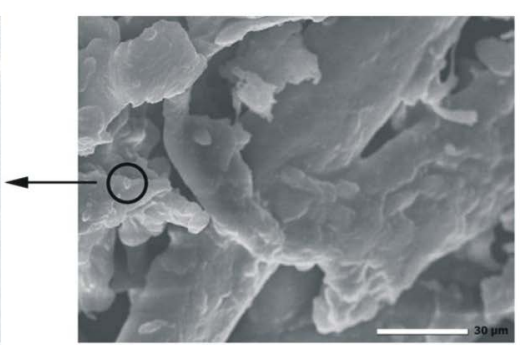

(b)

Figure 4. FESEM images of Cu-EFB powder, (a) (b) and EDX spectrum at the location of spectrum a, (c). 


\section{Conclusion}

Cu-EFB powders were synthesized via in-situ method with size $\sim 60$ - $100 \mathrm{~nm}$. The formation of copper nanoparticles on EFB powders were confirmed by XRD, FTIR spectrum, AFM, FESEM imaging and EDX, respectively. From the XRD profile, the crystallinity index of Cu-EFB powders was higher than untreated samples. The crystallinity of samples was also supported by FTIR; where the peak intensity of $896 \mathrm{~cm}^{-1}$ (C-O, amorphous cellulose) was reduced as the copper concentration increased. Besides that, from XRD spectrum at $2 \theta=42.3^{\circ}$ which attributed to copper signal was detected on Cu-EFB samples. Moreover, in EDX element analysis copper signal was also noticed. The incorporation of copper nanoparticles on EFB powder was identified via AFM and FESEM imaging. From AFM it was found that, the thickness of Cu-EFB samples were increased compared to untreated EFB samples. This suggested that, existences of nanoparticles on EFB were possible. This phenomenon was proved by FESEM image where small sphere particles were seen on EFB powder. The copper nanoparticles impregnated EFB powders can be used to develop composite materials with enhanced antimicrobial activities.

\section{Acknowledgements}

The authors would like to thank the Director General of MPOB for permission to publish this paper. The authors also wish to gratefully acknowledge the funding from MPOB to this study.

\section{References}

[1] Ahmad, E.E.M., Luyt, A.S. and Djoković, V. (2013) Thermal and Dynamic Mechanical Properties of Bio-Based Poly(furfuryl alcohol)/Sisal Whiskers Nanocomposites. Polymer Bulletin, 70, 1265-1276. http://dx.doi.org/10.1007/s00289-012-0847-2

[2] Tsioptsias, C. and Panayiotou, C. (2008) Preparation of Cellulose-Nanohydroxyapatite Composite Scaffolds from Ionic Liquid Solutions. Carbohydrate Polymers, 74, 99-105. http://dx.doi.org/10.1016/j.carbpol.2008.01.022

[3] Chowdhury, M.N.K., Beg, M.D.H., Khan, M.R. and Mina, M.F. (2013) Modification of Oil Palm Empty Fruit Bunch Fibers by Nanoparticle Impregnation and Alkali Treatment. Cellulose, 20, 1477-1490. http://dx.doi.org/10.1007/s10570-013-9921-7

[4] Tomšič, B., Simončič, B., Orel, B., Žerjav, M., Schroers, H., Simončič, A. and Samardžija, Z. (2009) Antimicrobial Activity of AgCl Embedded in a Silica Matrix on Cotton Fabric. Carbohydrate Polymers, 75, 618-626. http://dx.doi.org/10.1016/j.carbpol.2008.09.013

[5] Lee, H.J., Yeo, S.Y. and Jeong, S.H. (2003) Antibacterial Effect of Nanosized Silver Colloidal Solution on Textile Fabrics. Journal of Materials Science, 38, 2199-2204. http://dx.doi.org/10.1023/A:1023736416361

[6] Chowdhury, M.N.K., Beg, M.D.H., Khan, M.R. and Mina, M.F. (2013) Synthesis of Copper Nanoparticles and Their Antimicrobial Performances in Natural Fibres. Materials Letters, 98, 26-29. http://dx.doi.org/10.1016/j.matlet.2013.02.024

[7] Ramli, R., Khan, M.R., Chowdhury, N.K., Beg, M.D.H., Halim, R.M., Aziz, A.A., Ibrahim, Z. and Zainal, N.H. (2013) Development of $\mathrm{Cu}$ Nanoparticle Loaded Oil Palm Fibre Reinforced Nanocomposite. Advances in Nanoparticles, 4, 358-365. http://dx.doi.org/10.4236/anp.2013.24049

[8] El-Nahhal, I.M., Zourab, S.M., Kodeh, F.S., Selmane, M., Genois, I. and Babonneau, F. (2012) Nanostructured Copper Oxide-Cotton Fibers: Synthesis, Characterization, and Applications. International Nano Letters, 2, 1-5. http://dx.doi.org/10.1186/2228-5326-2-14

[9] Jeong, S.H., Hwang, Y.H. and Yi, S.C. (2005) Antibacterial Properties of Padded PP/PE Nonwovens Incorporating Nano-Sized Silver Colloids. Journal of Materials Science, 40, 5413-5418. http://dx.doi.org/10.1007/s10853-005-4340-2

[10] Lee, H.Y., Park, H.K., Lee, Y.M. and Park, S.B. (2007) A Practical Procedure for Producing Silver Nanocoated Fabric and Its Antibacterial Evaluation for Biomedical Applications. Chemical Communications, 28, 2959-2961. http://dx.doi.org/10.1039/B703034G

[11] Ong, H.R., Khan, M.R., Chowdhury, M.N.K., Yousuf, A. and Cheng, C.K. (2014) Synthesis and Characterization of $\mathrm{CuO} / \mathrm{C}$ Catalyst for the Esterification of Free Fatty Acid in Rubber Seed Oil. Fuel, 120, 195-201. http://dx.doi.org/10.1016/j.fuel.2013.12.015

[12] Ong, H.R., Khan, M.R., Ramli, R. and Yunus, R.M. (2014) Synthesis of Copper Nanoparticles at Room Temperature Using Hydrazine in Glycerol. Applied Mechanics and Materials, 481, 21-26.

http://dx.doi.org/10.4028/www.scientific.net/AMM.481.21 
[13] Inagaki, T., Siesler, H.W., Mitsui, K. and Tsuchikawa, S. (2010) Difference of the Crystal Structure of Cellulose in Wood after Hydrothermal and Aging Degradation: A NIR Spectroscopy and XRD Study. Biomacromolecules, 11, 2300-2305. http://dx.doi.org/10.1021/bm100403y

[14] Ong, H.R., Prasad, R., Khan, M.M.R. and Chowdhury, M.N.K. (2012) Effect of Palm Kernel Meal as Melamine Urea Formaldehyde Adhesive Extender for Plywood Application: Using a Fourier Transform Infrared Spectroscopy (FTIR) Study. Applied Mechanics and Materials, 121-126, 493-498. http://dx.doi.org/10.4028/www.scientific.net/AMM.121-126.493

[15] Tamez Uddin, M., Rukanuzzaman, M., Maksudur Rahman Khan, M. and Akhtarul Islam, M. (2009) Adsorption of Methylene Blue from Aqueous Solution by Jackfruit (Artocarpus heteropyllus) Leaf Powder: A Fixed-Bed Column Study. Journal of Environmental Management, 90, 3443-3450. http://dx.doi.org/10.1016/j.jenvman.2009.05.030

[16] Bhat, I.-U.-H., Abdul Khalil, H.P.S., Ismail, H. and Alshammari, T. (2011) Morphological, Spectroscopic, and Thermal Properties of Alkali-Treated and Chemically Modified Oil Palm Empty Fruit Bunch Fibers and Oil Palm Frond Fibers: A Comparative Study. BioResources, 6, 4673-4685.

[17] Öztürk, İ., Irmak, S., Hesenov, A. and Erbatur, O. (2010) Hydrolysis of Kenaf (Hibiscus cannabinus L.) Stems by Catalytical Thermal Treatment in Subcritical Water. Biomass and Bioenergy, 34, 1578-1585. http://dx.doi.org/10.1016/j.biombioe.2010.06.005

[18] Mihai, G.D., Meynen, V., Mertens, M., Bilba, N., Cool, P. and Vansant, E.F. (2010) ZnO Nanoparticles Supported on Mesoporous MCM-41 and SBA-15: A Comparative Physicochemical and Photocatalytic Study. Journal of Materials Science, 45, 5786-5794. http://dx.doi.org/10.1007/s10853-010-4652-8

[19] Yu, W., Xie, H., Chen, L., Li, Y. and Zhang, C. (2009) Synthesis and Characterization of Monodispersed Copper Colloids in Polar Solvents. Nanoscale Research Letters, 4, 465-470. http://dx.doi.org/10.1007/s11671-009-9264-3

[20] Ramyadevi, J., Jeyasubramanian, K., Marikani, A., Rajakumar, G. and Rahuman, A.A. (2012) Synthesis and Antimicrobial Activity of Copper Nanoparticles. Materials Letters, 71, 114-116. http://dx.doi.org/10.1007/s11671-009-9264-3 
Scientific Research Publishing (SCIRP) is one of the largest Open Access journal publishers. It is currently publishing more than 200 open access, online, peer-reviewed journals covering a wide range of academic disciplines. SCIRP serves the worldwide academic communities and contributes to the progress and application of science with its publication.

Other selected journals from SCIRP are listed as below. Submit your manuscript to us via either submit@scirp.org or Online Submission Portal.
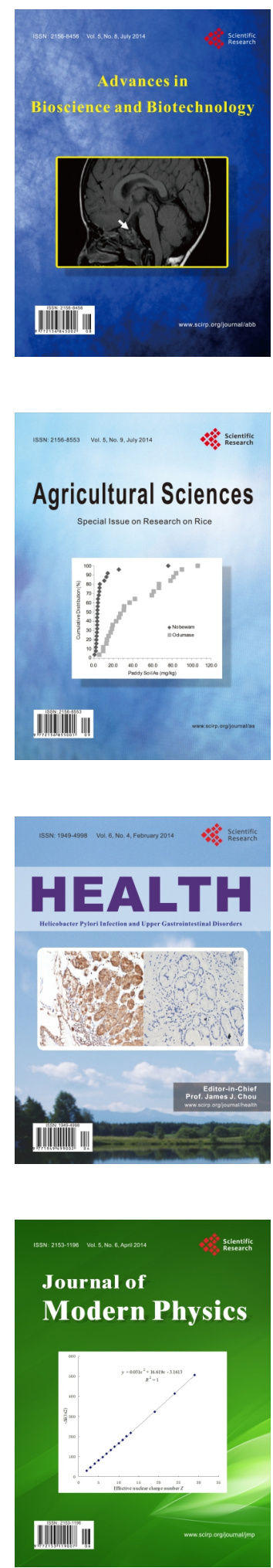
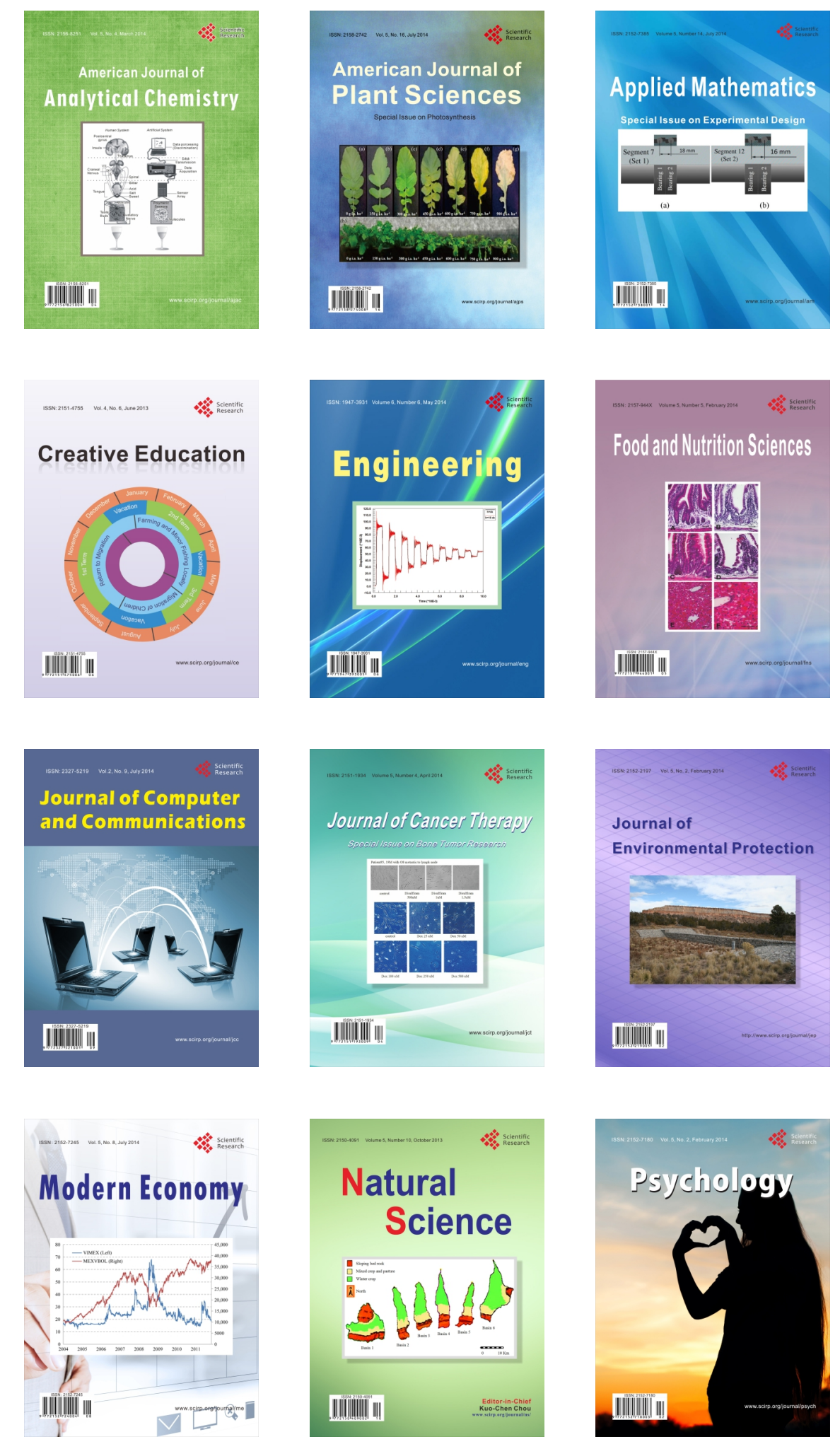